\title{
EVALUACIÓN PRODUCTIVA Y CALIDAD DEL GRANO DE CINCO HÍBRIDOS DE MAÍZ (Zea mays L.) EN DOS LOCALIDADES DE LA PROVINCIA DE LOS RÍOS
}

\author{
Gorki Teófilo Díaz Coronel ${ }^{1,2}$, Freddy Agustín Sabando Ávila ${ }^{1}$, Samir Zambrano Montes ${ }^{1}$ y \\ Gregorio Humberto Vásconez Montúfar ${ }^{1}$ \\ ${ }^{1}$ Unidad de Investigación Científica y Tecnológica, Universidad Técnica Estatal de Quevedo, $\mathrm{km} 1$ 1/2 \\ vía Quevedo - Santo Domingo de los Tsáchilas, C. P. 73. Quevedo, Los Ríos, Ecuador. \\ ${ }^{2}$ Facultad de Ciencias Pecuarias, Universidad Técnica Estatal de Quevedo, km 7 vía a El Empalme
}

RESUMEN

$\mathrm{L}$ a investigación se realizó durante la época lluviosa, en la Universidad Técnica Estatal de Quevedo e Instituto Tecnológico Agropecuario de Vinces. El objetivo fue determinar el comportamiento de cinco híbridos de maíz adaptados a las condiciones edafoclimáticas de la Cuenca del Río Guayas, en función de producción y calidad proteica de su semilla. Se empleó un diseño de bloques completamente al azar, con cinco tratamientos (híbridos: INIAP H-551, INIAP H-552, Vencedor R-8330, Brasilia 8501 y Dekalb 5005) y cuatro repeticiones, considerándose un análisis individual y combinado. Para las comparaciones de medias se utilizó la prueba de Tukey al 5\% de probabilidad. Existió un mayor rendimiento por hectárea en la localidad de Vinces $(\mathrm{P} \leq 0.05)$, esto se atribuye a la mayor longitud, número de hileras y al peso de granos por mazorca. En relación a la calidad nutritiva del grano, se determinó que el rendimiento de los híbridos "Dekalb 5005" y "Vencedor R-8330" es inversamente proporcional a la calidad de la proteína, debido a un bajo contenido de lisina.

Palabras claves: calidad proteica, aminoácidos, lisina, semillas.
Abstract
$T^{1}$ he research was conducted during the rainy season, at the Universidad Tecnica Estatal de Quevedo and the Instituto Tecnologico Agropecuario de Vinces. The objective was to determine the performance of five maize hybrids adapted to the soil and climatic conditions of the Guayas River basin, based on production and protein quality of seeds. A Complete Randomized Block Design was used along with five treatments (hybrids: INIAP H-551, INIAP H-552, R-8330 Winner, 8501 and Dekalb Brasilia 5005) and four replications, considering individual and combined analysis. For means comparisons Tukey test at $5 \%$ probability was used. There was a higher yield per hectare in the Vinces locality $(\mathrm{P} \leq 0.05)$, this is attributed to the increased length, number of rows and weight of grains per ear. In relation to the nutritional quality of grain it was determined that the performance of the hybrids 'Dekalb 5005' and 'Winner R-8330 was inversely proportional to the quality of the protein, due to a low content of lysine.

Key words: protein quality, amino acids, lysine, seeds.

\section{INTRODUCCIÓN}

$\mathrm{E}^{\mathrm{l}}$ maíz (Zea mays L.) es un producto agrícola estratégico para la seguridad alimentaria de la humanidad por su alto contenido energético, e incluso hoy en día, se habla de biocombustibles a base de maíz (etanol) como una fuente de energía alternativa, incrementándose aún más la demanda de este producto, tanto así, que los EE.UU. previó convertir el año 2007 la quinta parte de sus cosechas de maíz en etanol (Bourne, 2007).

La calidad del grano del maíz depende de su constitución física, que determinan la textura y dureza, $\mathrm{y}$ de su composición química, que define el valor nutricional. La importancia relativa de estas características dependerá del destino de la producción. Los mercados son cada vez más exigentes y se interesan por el contenido de proteína, aminoácidos, almidón, aceites y demás componentes, y paulatinamente se reducen en estos la tolerancia a sustancias contaminantes (INTA, 2006).

El valor nutritivo del maíz, es semejante al sorgo, y un poco menor que el trigo integral, la avena y el arroz. Como todos los cereales, el maíz es rico en carbohidratos y desequilibrado en proteína, vitaminas, y minerales (Chávez, 1972). El maíz, en comparación

Recibido: Enero, 2009. Aceptado: Febrero, 2009.

Publicado como ARTÍCULO en Ciencia y Tecnología 3: 15-23. 2009. con otros cereales, es un alimento de alto valor energético y poco tenor de proteína, la misma que al estar principalmente constituidas por zeína, es deficiente en los aminoácidos esenciales lisina y triptófano (Angeles, 1972; Villegas, 1972).

En el endospermo se localiza del 75 al $85 \%$ de la proteína total del grano, pero ésta es de muy baja calidad debido a la alta concentración de la prolamina zeína, fracción de la proteína soluble en alcohol y de poco contenido de los aminoácidos esenciales lisina y triptófano. En el embrión de la semilla se localiza del 15 al 25\% restante, que es de excelente calidad debido a la alta concentración de albúminas y globulinas, fracciones que son solubles en agua y en soluciones ácidas. Ambas tienen un alto contenido de lisina y triptófano (Poey, 1972).

El descubrimiento del gen mutante Opaco-2 (O2) en la composición de la proteína, ha renovado el interés de mejorar la calidad del maíz. El maíz O2 mostró un incremento significativo en el contenido de lisina y triptófano en el endospermo (Poey, 1972). Sin embargo, el gen $\mathrm{O} 2$ trajo consigo varias características fenotípicas no deseadas, como: textura blanda del endospermo, apariencia opaca del grano, mayor susceptibilidad a los 
hongos de la pudrición de la mazorca, susceptibilidad a insectos en campo y en el almacenamiento, mayor contenido de humedad del grano al momento de la cosecha, pericarpio más grueso, baja germinación de la semilla, y sobre todo, rendimientos bajos (Vasal, 1994).

Los investigadores de maíz en el CIMMYT (Centro Internacional de Mejoramiento de Maíz y Trigo), en México, están desarrollando procedimientos para combinar la interacción del gen $\mathrm{O} 2$ y de modificadores genéticos para obtener germoplasma de maíz con endospermo con proteínas de calidad (Vasal, 1994), y eliminando muchas de las respuestas indeseables correlacionadas.

En el Ecuador, los híbridos que actualmente se siembran han sido evaluados principalmente desde el punto de vista agronómico, y no la calidad de su grano. El análisis de calidad llega por lo general a nivel de contenido de proteínas y no al de aminoácidos. Por consiguiente, para recomendar variedades e híbridos de maíz es necesario considerar su adaptación a diferentes localidades considerando los parámetros de producción y calidad. En este contexto, la Unidad de Investigación Científica y Tecnológica (UICYT), desarrolló esta investigación, teniendo como objetivo de evaluar la producción y calidad del grano de cinco híbridos de maíz en las localidades de Quevedo y Vinces.

\section{Breve descripción del material genético}

El "Dekalb 5005", es un híbrido triple de última generación con una estructura de hojas erectas y un potencial de rendimiento alto. La floración femenina se da a los 54 días, con una altura de planta de $271 \mathrm{~cm}$ y una altura de inserción de la mazorca de $142 \mathrm{~cm}$. Su ciclo desde la siembra a la cosecha de 130 a 145 días. Tiene de 14 a 18 hileras de granos duros y anaranjados, con un peso de $300 \mathrm{~g}$ las 1,000 semillas y su promedio de producción es de 9,704 $\mathrm{kg} \mathrm{ha}^{-1}$.

El "Vencedor R-8330", es un híbrido que se dio como resultado de cinco años de investigación y fue seleccionado entre 41 materiales por sus sobresalientes cualidades agronómicas y de rendimiento. La floración femenina es de 53 a 54 días, con una altura de planta de $240 \mathrm{~cm}$ y una altura de inserción de la mazorca de 120 $\mathrm{cm}$. Es tolerante a enfermedades. Tiene una longitud de mazorca de $18.8 \mathrm{~cm}$ con 14 a 18 hileras de granos semidentados. Es tolerante al acame de raíz y tallo. Posee un $10.59 \%$ de proteína, $3.37 \%$ de fibra y $7.46 \%$ de grasa (Agripac, s.f.). A nivel experimental, en el año 2002, en la época lluviosa alcanzó un rendimiento promedio de 6,$243 ; 7,434$ y 7,840 $\mathrm{kg} \mathrm{ha}^{-1}$ en las localidades de Ventanas, Quevedo y Balzar, respectivamente (Agripac, s.f.).

El "Brasilia 8501", es un híbrido bien adaptado al Litoral Ecuatoriano, lo que ha permitido obtener altos rendimientos. Es un híbrido triple de buen rendimiento y cobertura de mazorca. Tiene una altura de planta de $240 \mathrm{~cm}$ y una altura de inserción de la mazorca de $130 \mathrm{~cm}$, es tolerante a enfermedades fungosas (Agripac, s.f.). Tiene una longitud de mazorca de $19 \mathrm{~cm}$ con 14 a 18 hileras de granos semidentado y un peso de 100 semillas de $35.7 \mathrm{~g}$, resistente al acame de raíz y tallo. En promedio alcanza un rendimiento de $7,725 \mathrm{~kg} \mathrm{ha}^{-1}$ (Agripac, citado por Zambrano, 2002).

El "INIAP H-551", está formado por la cruza de tres líneas endogámicas: " $\mathrm{S}_{4}$ B-523 x $\mathrm{S}_{4}$ B-521" $\mathrm{x}$ "S $\mathrm{S}_{4}$ B-520". Estas líneas fueron obtenidas por autopolinizaciones sucesivas, y provienen de diferentes maíces básicos de amplia base genética y buen potencial de rendimiento. En la época lluviosa, emite la flor femenina a los 50 a 52 días y en la época seca entre los 60 a 62 días, su ciclo de siembra a cosecha es de 120 días. La altura promedio de la planta es de 216 a $240 \mathrm{~cm}$ y la altura de inserción de mazorca es de 114 a $120 \mathrm{~cm}$. Es tolerante a enfermedades foliares y susceptible a los insectos plagas de mayor incidencia. Tiene una longitud de mazorca de entre 16.5 y $19.5 \mathrm{~cm}$, contando con 12 a 16 hileras de grano, de textura cristalina. A nivel experimental alcanza un rendimiento de $7,273 \mathrm{~kg} \mathrm{ha}^{-1}$, con $13 \%$ de humedad (INIAP, 1990).

El "INIAP H-552", está formado por la cruza de tres líneas de maíz con el $93.75 \%$ de homocigosis. En la época lluviosa y seca, emite su flor masculina a los 54 a 62 días y la flor femenina a los 55 a 64, respectivamente; su ciclo de siembra a cosecha es de 120 días. La altura promedio de la planta es de $240 \mathrm{~cm}$ y la altura de inserción de mazorca de $120 \mathrm{~cm}$. Es resistente al acame de raíz y a la ruptura del tallo bajo la mazorca. Es tolerante a enfermedades foliares y susceptible a los insectos plagas de mayor incidencia. Tiene una longitud de mazorca de entre 16 a $18 \mathrm{~cm}$ y 4.5 a $4.9 \mathrm{~cm}$ de diámetro, contando con 12 a 14 hileras de grano, de textura cristalina. El peso de 1,000 semillas con el 13\% de humedad es de $215 \mathrm{~g}$. A nivel experimental alcanza un rendimiento de 7,100 $\mathrm{kg} \mathrm{ha}^{-1}$ (INIAP, 2003).

\section{Materiales y Métodos}

\section{Situación de las localidades en estudio}

Ta investigación se llevó a cabo durante la época lluUviosa del año 2007, en dos localidades de la provincia de Los Ríos - Ecuador. En Quevedo, en la finca experimental "La María" de la Universidad Técnica Estatal de Quevedo (UTEQ), ubicada en el Km 7 vía Quevedo - Empalme, ubicada dentro de las coordenadas geográficas $79^{\circ} 27^{\prime}$ de longitud Oeste y $01^{\circ} 06^{\prime}$ de latitud Sur a unos $73 \mathrm{msnm}$. En Vinces, en el Instituto Tecnológico Agropecuario de Vinces (ITAV), ubicado 
en el Km 1,5 vía Vinces - Palestina, ubicado dentro de las coordenadas geográficas $79^{\circ} 47^{\prime}$ de longitud Oeste y $01^{\circ} 32^{\prime}$ de latitud Sur a unos $41 \mathrm{msnm}$. De acuerdo al sistema de clasificación de las zonas de vida de Holdridge, la localidad de Quevedo se encuentra dentro de la zona ecológica bh-T y la localidad de Vinces en la zona ecológica bs-T.

\section{Tratamientos}

Los tratamientos en estudio fueron los híbridos comerciales de maíz: "Dekalb 5005", "Vencedor R-8330", "Brasilia 8501", "INIAP H-551" e "INIAP H-552".

\section{Diseño experimental}

Se empleó un diseño de bloques completos al azar, con cinco tratamientos (híbridos) y cuatro repeticiones. Además, se realizó un análisis individual y combinado. Para comparar las medias de los tratamientos se utilizó la prueba de Tukey al 5\% de probabilidad. De acuerdo a Martínez (1996), el modelo lineal es el siguiente: $\mathrm{y}_{\mathrm{ijk}}=\mu+\pi_{\mathrm{i}}+\beta_{\mathrm{ij}}+\tau_{\mathrm{k}}+(\pi \tau)_{\mathrm{ik}}+\mathrm{e}_{\mathrm{ijk}}$. Donde: $\mathrm{y}_{\mathrm{ijk}}$ $=$ Valor de la característica observado en la localidad $i$, en el bloque $j$, y con el tratamiento $k ; \mu=$ Efecto común de todas las observaciones; $\pi_{\mathrm{i}}=$ Efecto de la localidad $i ; \beta_{\mathrm{ij}}=$ Efecto del bloque $j$ dentro de la localidad $i ; \tau_{\mathrm{k}}=$ Efecto del tratamiento $k ;(\pi \tau)_{\mathrm{ik}}=$ Efecto de la interacción entre el tratamiento $k$ y la localidad $i ; \mathrm{e}_{\mathrm{ijk}}=$ Error de observación sobre la unidad experimental ijk.

\section{Descripción del experimento}

El tamaño del experimento fue de $30.0 \times 17.5$ $\mathrm{m}$, con una superficie total de $525.0 \mathrm{~m}^{2}$. Las dimensiones de la parcela experimental fue de $6.0 \times 3.6 \mathrm{~m}$, con una superficie de $21.60 \mathrm{~m}^{2}$. La superficie de la parcela útil fue de $6.0 \times 1.8 \mathrm{~m}$, con una superficie de $10.8 \mathrm{~m}^{2}$. La distancia entre hileras y plantas de maíz fue de $0.9 \mathrm{x}$ $0.2 \mathrm{~m}$, lo que representa una densidad por hectárea de 55,555 plantas.

\section{Variables registradas y metodología utilizada}

Se midieron variables agronómicas, productivas y de calidad de la semilla, como: días a floración y maduración; longitud, diámetro, hileras y peso de semillas por mazorca; peso de mil semillas, y rendimiento por hectárea; y finalmente se realizó un análisis proximal, y de aminoácidos a la semilla originada en la cosecha.

La variable días a floración resulta al cuantificar el periodo transcurrido desde la siembra hasta cuando el
$50 \%$ de las plantas que conforman la parcela útil hayan florecido. Los días a maduración resulta al cuantificar el periodo transcurrido desde la siembra hasta cuando el $50 \%$ de las plantas de la parcela útil adquirieron la coloración característica en plantas maduras de maíz.

En las variables, longitud de mazorca $(\mathrm{cm})$, diámetro de la mazorca ( $\mathrm{mm})$, hileras por mazorca, peso de semillas por mazorca $(\mathrm{g})$ y peso de mil semillas $(\mathrm{g})$, se evaluó diez mazorcas tomadas al azar en la parcela útil de cada unidad experimental. Para determinar el diámetro de la mazorca, se consideró en el tercio medio de cada mazorca, y para el peso de semillas por mazorca y peso de mil semillas se utilizó una balanza Scout Pro de 2,000 g con una precisión de \pm 0.1 , para cuantificar estas dos últimas variables se ajustó la humedad de la semilla al 13\%. El rendimiento se determinó en función de la cosecha del área útil, de cada parcela experimental, haciendo uso de la siguiente fórmula:

$$
R U=\frac{R A(100-H A)}{(100-H D)} \times \frac{10,000}{A U}
$$

Donde:

$$
\begin{aligned}
& R U=\text { Rendimiento por hectárea, } \mathrm{kg} \\
& R A=\text { Rendimiento actual, } \mathrm{kg} \\
& H A=\text { Humedad actual, } \% \\
& H D=\text { Humedad deseada, } \% \\
& A U=\text { Área útil, } \mathrm{m}^{2} .
\end{aligned}
$$

\section{Calidad nutritiva del grano}

Para determinar la calidad nutritiva del grano se realizó un análisis proximal (humedad, cenizas, proteínas, fibra, grasa, elementos libres de nitrógeno), y de aminoácidos. Para el efecto se envió una muestra de 1,000 g por híbrido de las dos localidades de siembra al Laboratorio de Nutrición y Calidad, de la Estación Experimental Santa Catalina del INIAP.

\section{Resultados}

\section{Días a floración y maduración}

\begin{abstract}
A 1 evaluar los días a floración y maduración, se registraron diferencias para el factor localidad $(\mathrm{P}<0.05)$. En la localidad de Vinces se encontró mayores días a floración; en cambio, en Quevedo se reportaron los mayores días a maduración. En los días a floración y maduración, se registraron diferencias entre los híbridos. Los híbridos "Dekalb 5005" y "Vencedor 8330 " presentaron mayores días a floración con 56.63 y 56.25, respectivamente. Por otra parte, El híbrido "Dekalb 5005" registró la maduración más tardía con 118.50 (Cuadro 1).
\end{abstract}


Cuadro 1. Días a floración y maduración en cinco híbridos de maíz, durante la época lluviosa, en las localidades de Quevedo y Vinces. 2007

\begin{tabular}{lcc}
\hline \multicolumn{1}{c}{ Factores } & Días a Floración & Días a maduración \\
\hline Localidad & $57.65 \mathrm{a}^{\dagger}$ & $101.20 \mathrm{~b}$ \\
Vinces & $51.00 \mathrm{~b}$ & $115.40 \mathrm{a}$ \\
Quevedo & & \\
Híbrido & $56.63 \mathrm{a}$ & $118.50 \mathrm{a}$ \\
Dekalb 5005 & $56.25 \mathrm{a}$ & $110.75 \mathrm{~b}$ \\
Vencedor 8330 & $55.25 \mathrm{~b}$ & $110.25 \mathrm{~b}$ \\
Brasilia 8501 & $52.00 \mathrm{c}$ & $101.50 \mathrm{c}$ \\
INIAP H-551 & $51.50 \mathrm{~d}$ & $100.50 \mathrm{~d}$ \\
INIAP H-552 & 54.32 & 108.3 \\
$\overline{\boldsymbol{X}}$ & 1.16 & 0.43 \\
CV (\%) & &
\end{tabular}

Promedios con letras iguales no son diferentes estadísticamente, de acuerdo a la prueba de Tukey (P>0.05)

En los días a floración, la interacción "Localidades por híbridos" existió diferencia $(\mathrm{P}<0.05)$. Los híbridos presentaron un rango de días a floración amplio en la localidad de Quevedo, a diferencia de lo observado en la localidad de Vinces, donde el rango de días a floración fue mucho más estrecho. Se observaron mayores días a la floración en la localidad de Vinces, siendo los híbridos "INIAP H-551" e "INIAP H-552" los que presentaron menores días a floración en Quevedo y Vinces (Figura 1).

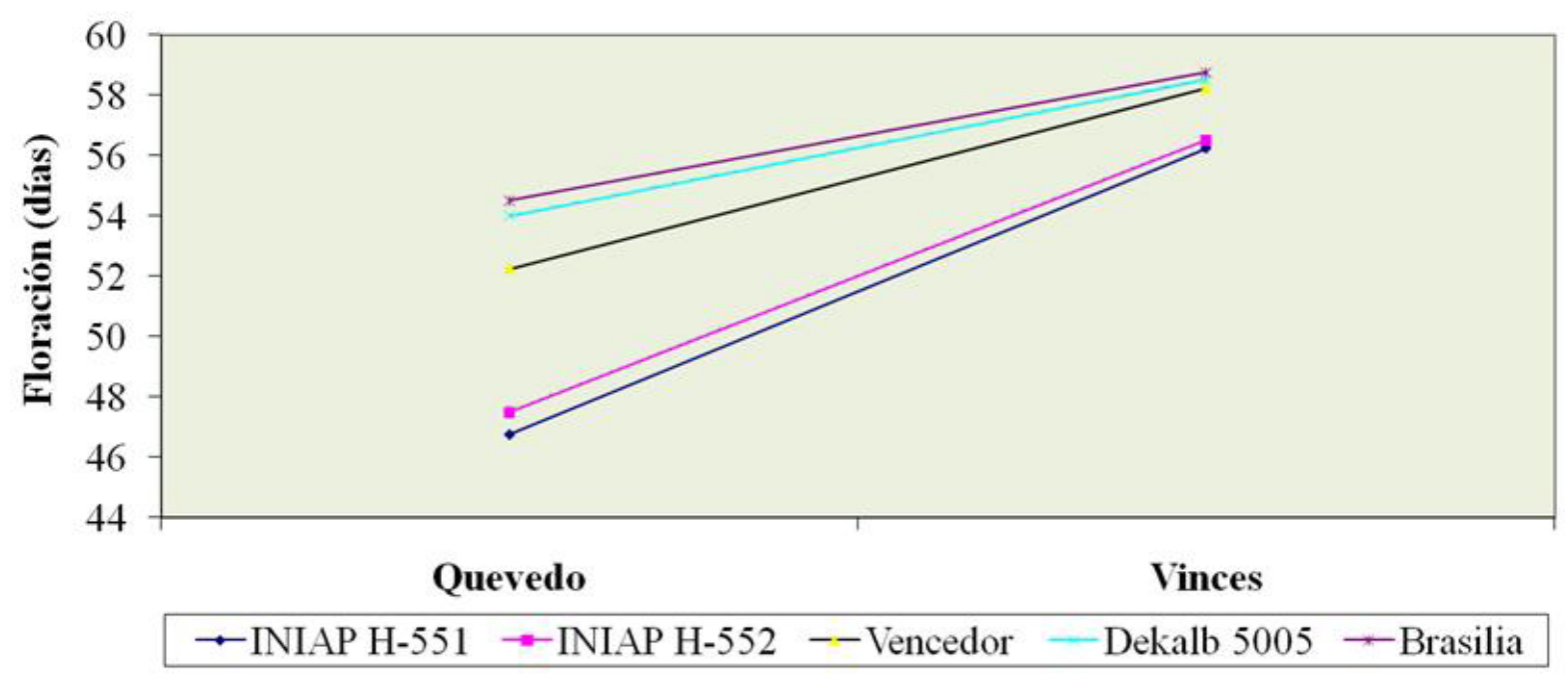

Figura 1. Interacción "Localidades $x$ híbridos" en la floración de cinco híbridos de maíz, durante la época lluviosa, en las localidades de Quevedo y Vinces. 2007

En los días a maduración, la interacción "Localidades por híbridos" existió diferencia $(\mathrm{P}<0.05)$. Los híbridos presentaron un rango de maduración mayor en la localidad de Quevedo. En esta localidad, los híbridos presentaron un mayor número de días a maduración que en Vinces; siendo el "INIAP H-551" e "INIAP H-552" los de menor días a maduración, en ambas localidades (Figura 2). 


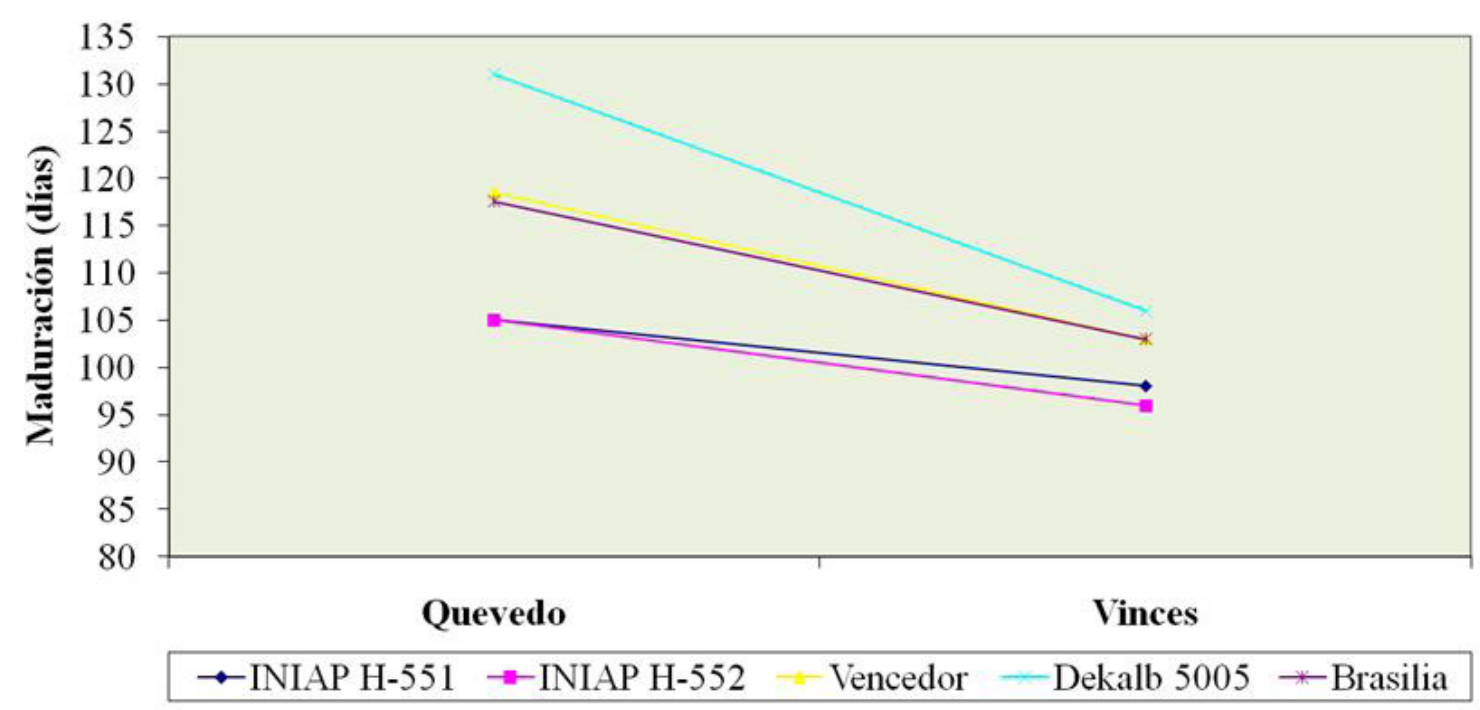

Figura 2. Interacción "Localidades x híbridos” en la maduración de cinco híbridos de maíz, durante la época lluviosa, en las localidades de Quevedo y Vinces. 2007

En la longitud de mazorca y número de hileras por mazorcas se encontraron diferencias $(\mathrm{P}<0.05)$, no así, en el diámetro de mazorca y en el peso de semillas por mazorca. En la localidad de Vinces se registró la mayor longitud de mazorca y número de hileras por mazorca. El hibrido "Dekalb 5005" presentó la mayor longitud y número de hileras por mazorca con $18.41 \mathrm{~cm}$ y 15.51 hileras, seguido del híbrido "Vencedor 8330 " con 17.48 y 14.81 , respectivamente, este último híbrido presentó el mejor diámetro de mazorca con $5.15 \mathrm{~cm}, \mathrm{y}$ en cuanto a peso de semillas por mazorca, el hibrido "Dekalb 5005" fue el que más peso alcanzó, con 176.39 g (Cuadro 2).

Cuadro 2.Longitud de mazorca (LM), diámetro de mazorca (DM), hileras por mazorca (HM) y peso de semillas por mazorca (PSM) de cinco híbridos de maíz, durante la época lluviosa, en las localidades de Quevedo y Vinces. 2007

\begin{tabular}{lcccc}
\hline \multicolumn{1}{c}{ Factores } & LM, cm & DM, cm & HM & PSM, $\mathbf{g}$ \\
\hline Localidad & & & & \\
Vinces & $18.14 \mathrm{a}^{\dagger}$ & $4.79 \mathrm{a}$ & $14.19 \mathrm{a}$ & $134.32 \mathrm{a}$ \\
Quevedo & $15.37 \mathrm{~b}$ & $4.68 \mathrm{a}$ & $13.58 \mathrm{~b}$ & $138.69 \mathrm{a}$ \\
Híbrido & & & & \\
Dekalb 5005 & $18.41 \mathrm{a}$ & $4.96 \mathrm{a}$ & $15.51 \mathrm{a}$ & $176.39 \mathrm{a}$ \\
Vencedor 8330 & $17.48 \mathrm{a}$ & $5.15 \mathrm{a}$ & $14.81 \mathrm{a}$ & $151.41 \mathrm{~b}$ \\
Brasilia 8501 & $16.09 \mathrm{~b}$ & $4.76 \mathrm{ab}$ & $13.13 \mathrm{~b}$ & $134.66 \mathrm{~b}$ \\
INIAP H-551 & $15.50 \mathrm{~b}$ & $4.44 \mathrm{~b}$ & $13.25 \mathrm{~b}$ & $109.34 \mathrm{c}$ \\
INIAP H-552 & $16.33 \mathrm{~b}$ & $4.39 \mathrm{~b}$ & $12.74 \mathrm{~b}$ & $110.74 \mathrm{c}$ \\
\hline $\bar{X}$ & 16.76 & 4.74 & 13.88 & 136.5 \\
CV (\%) & 4.52 & 5.96 & 4.26 & 8.79 \\
\hline
\end{tabular}

${ }_{\dagger}$ Promedios con letras iguales no son diferentes estadísticamente, de acuerdo a la prueba de Tukey $(\mathrm{P}>0.05)$

La interacción "Localidades por híbridos" fue para la longitud de mazorcas $(\mathrm{P}<0.05)$. En la localidad de Quevedo, el híbrido "Brasilia 8501" fue el que pre- sentó la menor longitud de mazorca; en cambio, en la localidad de Vinces fueron los híbridos "INIAP-H-551" e "INIAP-H-552" (Figura 3) 


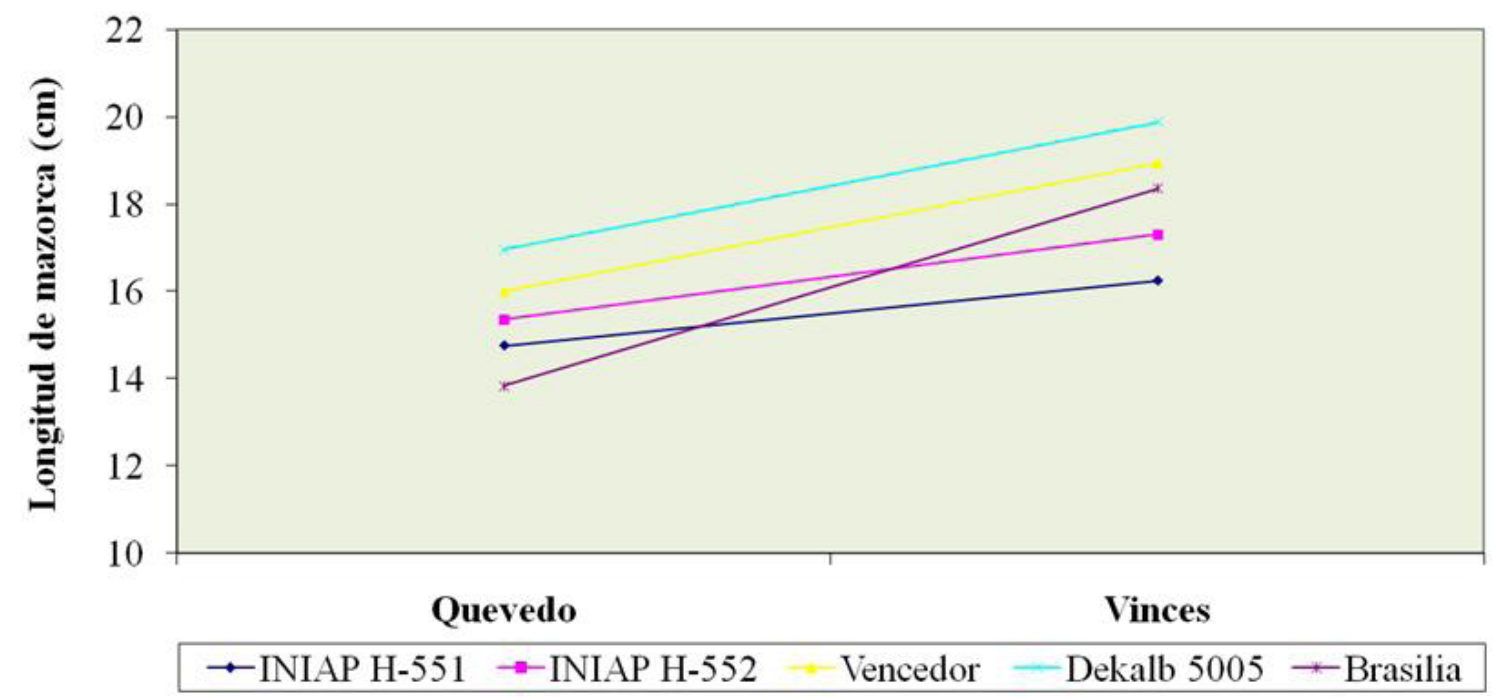

Figura 3. Interacción "Localidades $x$ híbridos" en la longitud de mazorcas de cinco híbridos de maíz, durante la época lluviosa, en las localidades de Quevedo y Vinces. 2007

Peso de mil semillas y rendimiento por hectárea

En el peso de mil semillas y rendimiento por hectárea se presentaron diferencias para localidades $(\mathrm{P}<0.05)$. La localidad de Vinces fue la que presentó el mayor peso de 1,000 semillas y rendimiento por hectárea, con 362.67 g y $5,982.00 \mathrm{~kg}$, respectivamente, mientras que la localidad de Quevedo registró un peso 1,000 semillas de $315.85 \mathrm{~g}$ y un rendimientos de $5213 \mathrm{Kg} \mathrm{ha}^{-1}$. Se observó que hubo diferencia estadísticas para los híbridos $(\mathrm{P}<0.05)$. Los híbridos "Brasilia 8501" e INIAP
H-552" registraron el mayor peso de 1,000 semillas con 367.84 y 354.33 g, respectivamente. Situación que contrasta en el rendimiento, ya que los híbridos "Dekalb 5005" y "Vencedor 8330" alcanzaron las mayores producciones con $7,738.0$ y $6,373.7 \mathrm{~kg} \mathrm{ha}^{-1}$, respectivamente; los que menor rendimiento presentaron, fueron, los híbridos "INIAP H-551" e "INIAP H-552" con 4,297.2 y 4,215.6 kg ha-1, respectivamente. No se presentó significancia estadística para la interacción "localidades por híbridos" (Cuadro 3).

Cuadro 3. Peso de mil semillas (PMS) y rendimiento por hectárea (RH) de cinco híbridos de maíz, durante la época lluviosa, en las localidades de Quevedo y Vinces. 2007

\begin{tabular}{lcc}
\hline \multicolumn{1}{c}{ Factores } & PMS, $\mathbf{g}$ & RH, $\mathbf{k g}$ \\
\hline Localidad & $362.67 \mathrm{a}^{\dagger}$ & $5982.0 \mathrm{a}$ \\
Vinces & $315.85 \mathrm{~b}$ & $5213.0 \mathrm{~b}$ \\
Quevedo & & \\
Híbrido & $309.96 \mathrm{c}$ & $7738.0 \mathrm{a}$ \\
Dekalb 5005 & $334.96 \mathrm{bc}$ & $6373.7 \mathrm{~b}$ \\
Vencedor 8330 & $367.84 \mathrm{a}$ & $5362.8 \mathrm{bc}$ \\
Brasilia 8501 & $329.21 \mathrm{bc}$ & $4297.2 \mathrm{c}$ \\
INIAP H-551 & $354.33 \mathrm{ab}$ & $4215.6 \mathrm{c}$ \\
INIAP H-552 & 339.26 & 547.46 \\
$\overline{\boldsymbol{X}}$ & 6.32 & 14.76 \\
CV (\%) & &
\end{tabular}




\section{Calidad nutritiva del grano}

En el análisis proximal del grano de los cinco híbridos comerciales de maíz, se encontró que el mayor porcentaje de proteína, en promedio, lo presentaron los híbridos: "Vencedor 8330" e "INIAP-H-552" con 12.2, en ambos casos. El menor porcentaje de proteínas, en promedio de las dos localidades, lo presentó los híbridos: "Dekalb 5005" y "Brasilia 8501" con 10.6 y 10.7 , respectivamente (Cuadro 4).

Cuadro 4. Análisis proximal del grano de cinco híbridos de maíz, durante la época lluviosa, en las localidades de Quevedo y Vinces. 2007

\begin{tabular}{lccccccccc}
\hline \multirow{2}{*}{ HIBRIDO } & \multicolumn{3}{c}{ Humedad (\%) } & \multicolumn{3}{c}{ Cenizas (\%) $^{\dagger}$} & \multicolumn{3}{c}{ EE (\%) } \\
\cline { 2 - 10 } & Quevedo & Vinces & $\overline{\boldsymbol{X}}$ & Quevedo & Vinces & $\overline{\boldsymbol{X}}$ & Quevedo & Vinces & $\overline{\boldsymbol{X}}$ \\
\hline Dekalb 5005 & 13.2 & 13.4 & 13.3 & 1.5 & 1.6 & 1.6 & 4.3 & 4.5 & 4.4 \\
Vencedor 8330 & 11.9 & 14.3 & 13.1 & 1.6 & 1.6 & 1.6 & 5.0 & 4.9 & 5.0 \\
Brasilia 8501 & 12.8 & 14.4 & 13.6 & 1.8 & 1.7 & 1.8 & 5.0 & 4.5 & 4.8 \\
INIAP-H-551 & 12.7 & 14.2 & 13.5 & 1.6 & 1.5 & 1.6 & 5.0 & 5.4 & 5.2 \\
INIAP-H-552 & 12.1 & 12.6 & 12.4 & 1.9 & 1.4 & 1.7 & 5.2 & 4.1 & 4.7 \\
\hline \multirow{2}{*}{ HIBRIDO } & \multicolumn{2}{c}{ Proteínas (\%) } & \multicolumn{3}{c}{ Fibra (\%) } & & \multicolumn{2}{c}{ ELN (\%) $)^{\dagger}$} \\
\cline { 2 - 10 } & Quevedo & Vinces & $\overline{\boldsymbol{X}}$ & Quevedo & Vinces & $\overline{\boldsymbol{X}}$ & Quevedo & Vinces & $\overline{\boldsymbol{X}}$ \\
\hline Dekalb 5005 & 11.0 & 10.2 & 10.6 & 3.2 & 3.5 & 3.4 & 80.0 & 80.0 & 80.0 \\
Vencedor 8330 & 12.4 & 11.9 & 12.2 & 3.1 & 3.0 & 3.1 & 78.0 & 78.7 & 78.4 \\
Brasilia 8501 & 10.6 & 10.7 & 10.7 & 3.3 & 3.4 & 3.4 & 79.3 & 80.0 & 79.7 \\
INIAP-H-551 & 11.6 & 11.8 & 11.7 & 3.0 & 3.4 & 3.2 & 78.9 & 78.0 & 78.5 \\
INIAP-H-552 & 12.0 & 12.3 & 12.2 & 3.3 & 3.2 & 3.3 & 77.7 & 79.0 & 78.4 \\
\hline
\end{tabular}

${ }^{\dagger}$ Resultados en base seca

Al analizar el perfil de aminoácidos en los híbridos de maíz estudiados, donde, los aminoácidos lisina y triptófano, que son constituyentes de la zeína, determinan la calidad de la proteína. Los híbridos "Dekalb 5005", "Vencedor 8330" y "INIAP H-552" registraron el menor contenido de lisina en su proteína. Los híbridos "INIAP H-551" y "Brasilia 8501" presentaron los mayores contenidos de lisina. Los híbridos "Dekalb 5005" e "INIAP H-551" presentaron los menores contenido de triptófano con 0.5 y $0.6 \mathrm{mg}$ por cada $100 \mathrm{~g}$ de proteína, respectivamente; en cambio, Los híbridos "Vencedor 8330", "Brasilia 8501" e "INIAP-H-552" registraron el mayor contenido de triptófano con $0.7 \mathrm{mg}$ por cada $100 \mathrm{~g}$ de proteína (Cuadro 5).

Cuadro 5. Contenido de aminoácidos (miligramos por cada 100 g de proteína) del grano de cinco híbridos de maíz, durante la época lluviosa en las localidades de Quevedo y Vinces. 2007

\begin{tabular}{|c|c|c|c|c|c|c|c|c|c|c|c|c|c|c|c|}
\hline \multirow{2}{*}{ Aminoácido } & \multicolumn{3}{|c|}{ Dekalb 5005} & \multicolumn{3}{|c|}{ Vencedor R-8330 } & \multicolumn{3}{|c|}{ Brasilia 8501} & \multicolumn{3}{|c|}{ INIAP H-551 } & \multicolumn{3}{|c|}{ INIAP H-552 } \\
\hline & $\underline{1 /}$ & $\underline{21}$ & $\underline{\mathbf{3} /}$ & $\underline{1 /}$ & $\underline{21}$ & $\underline{3 /}$ & $\underline{1} /$ & $\underline{21}$ & $\underline{\mathbf{3} /}$ & $\underline{1}$ & $\underline{21}$ & $\underline{\mathbf{3} /}$ & $\underline{1 /}$ & $\underline{2 l}$ & $\underline{3 /}$ \\
\hline Isoleucina & 4.3 & 3.2 & 3.8 & 4.7 & 4.4 & 4.6 & 4.8 & 3.7 & 4.3 & 4.2 & 3.8 & 4.0 & 4.2 & 3.9 & $\overline{4.1}$ \\
\hline Leucina & 13.5 & 10.6 & 12.1 & 9.0 & 16.4 & 12.7 & 18.0 & 13.8 & 15.9 & 14.6 & 15.0 & 14.8 & 15.9 & 14.2 & 15.1 \\
\hline Lisina & 3.1 & 2.7 & 2.9 & 2.2 & 3.6 & 2.9 & 3.3 & 2.7 & 3.0 & 3.3 & 3.5 & 3.4 & 3.0 & 2.8 & 2.9 \\
\hline Metionina & 1.4 & 1.1 & 1.3 & 1.9 & 0.9 & 1.4 & 1.1 & 0.9 & 1.0 & 1.1 & 1.3 & 1.2 & 0.9 & 0.4 & 0.7 \\
\hline Fenilalanina & 5.8 & 4.6 & 5.2 & 6.8 & 7.0 & 6.9 & 7.5 & 5.9 & 6.7 & 6.6 & 6.1 & 6.4 & 6.6 & 5.7 & 6.2 \\
\hline Treonina & 4.3 & 3.1 & 3.7 & 3.6 & 4.2 & 3.9 & 4.9 & 3.7 & 4.3 & 4.0 & 3.8 & 3.9 & 4.0 & 4.0 & 4.0 \\
\hline Triptófano & 0.5 & 0.4 & 0.5 & 0.8 & 0.5 & 0.7 & 0.5 & 0.8 & 0.7 & 0.6 & 0.6 & 0.6 & 0.8 & 0.6 & 0.7 \\
\hline Valina & 5.0 & 4.1 & 4.6 & 5.6 & 6.2 & 5.9 & 6.1 & 5.1 & 5.6 & 5.5 & 5.0 & 5.3 & 5.6 & 5.2 & 5.4 \\
\hline
\end{tabular}




\section{Discusión}

E n la localidad de Vinces se encontraron los mayores días a floración. En la localidad de Quevedo se registraron los mayores días a maduración. Así mismo, el híbrido "Dekalb 5005" presentó el mayor número de días a floración y a maduración que el resto de híbridos, lo cual es una condición genética y una respuesta al medio ambiente, lo cual concuerda con los resultados encontrados por LiuBa (2006), quien evaluó 12 híbridos de maíz introducidos de Brasil y seis híbridos comerciales, en la época lluviosa, en la localidad de Quevedo.

En la localidad de Quevedo se registró el mayor número de días a maduración de los híbridos, lo que se atribuye, a la mayor cantidad de humedad que se almacena en los suelos de Quevedo. Al evaluar el efecto de la localidad sobre los híbridos de maíz, la floración y la maduración tienen una mayor dispersión en la localidad de Quevedo, debido posiblemente a la menor luminosidad y mayor humedad de esta localidad en relación con la localidad de Vinces.

En el análisis de las mazorcas por localidades, en Vinces se reportó la mayor longitud de mazorca, número de hileras por mazorca y peso de 1,000 semillas. A la longitud de mazorca, número de hileras por mazorca y peso de 1,000 semillas, se atribuye los mejores rendimientos por hectárea registrados en la localidad de Vinces. El peso del grano por mazorca no presentó diferencias para localidades.

En la localidad de Quevedo, la semilla de los híbridos de maíz registraron, en promedio, un contenido de proteína de $11.5 \%$ con un rango de 1.8 , en lo que respecta a fibra se observó, en promedio, que los híbridos registran apenas un $3.2 \%$ con un rango de 0.3 , similar respuesta se observó en la localidad de Vinces. Se sabe que el maíz, en comparación con otros cereales, es un alimento de alto valor energético y con bajo contenido de fibra y proteína. La proteína del maíz por consistir principalmente en zeína, es deficiente en los aminoácidos lisina y triptófano (Angeles, 1972).

En relación a la calidad nutritiva del grano se determinó que en híbridos como el "Dekalb 5005" y "Vencedor R-8330", el rendimiento fue inversamente proporcional a la calidad de la proteína, debido a un bajo contenido de lisina; en cuanto a localidades, en Quevedo, donde el nivel de rendimiento fue menor, se reportó un mayor nivel de aminoácidos, mientras que, en Vinces, donde el nivel de rendimiento fue mayor, se reportó un menor contenido de aminoácidos. También se puede señalar que la calidad de la proteína es una cuestión genética. Así, en el híbrido "INIAP H-551" se encontró un buen nivel de lisina (3.4 mg por cada $100 \mathrm{~g}$ de proteína) teniendo bajos rendimientos por unidad de superficie. Aunque, sus niveles de lisina no llega $4.2 \mathrm{mg}$ por cada $100 \mathrm{~g}$ de proteína, el cual es recomendado por la FAO de (Pradilla et al., 1973). Los niveles de lisina y triptófano son bajos en los híbridos estudiados, lo que indica que estos no han sido mejorados en función de la calidad proteica del grano.

Los híbridos de maíz "Dekalb 5005" y "Vencedor 8330", registraron los mayores rendimientos por hectárea con 7,738.0 y 6,373.7 kg, pero el tenor de lisina en la proteína es inferior al observado en el híbrido "INIAP-551", el cual apenas registra un rendimiento por hectárea de 4,297.2 kg. De acuerdo a Poey (1973), un porcentaje alto de proteína en la semilla de maíz, implica una reducción de los almidones del endospermo, reflejándose en una baja producción de granos. Por otro lado, es cierto que cualquier esfuerzo encaminado a mejorar la calidad o cantidad de la proteína debe estar asociado a aumentar, o al menos mantener, los rendimientos del maíz, comparables a los que se obtienen en las variedades e híbridos comerciales. Ahora se sabe que los defectos asociados con el gen $\mathrm{O} 2$ han sido reducidos, de tal manera que se constituye en una importante alternativa para el mejoramiento de la calidad proteica del grano de maíz (Vasal, 1994).

\section{Conclusiones}

Q $\mathrm{n}$ Quevedo se reportaron menores días a floración con 51.0 y mayores días a maduración con 115.5, mientras que en Vinces se reportaron mayores días a la floración con 57.6 y menores días a la maduración con 101.2.

Los híbridos "Dekalb 5005" y "Brasilia 8501" registraron el mayor número de días a floración; el híbrido "Dekalb 5005" fue el más tardío, en cuanto al ciclo vegetativo, en ambas localidades.

En las localidades de Quevedo y Vinces, el hibrido "Dekalb 5005" presenta la mayor longitud de mazorca, superando los 16 y $19 \mathrm{~cm}$, respectivamente.

La localidad de Vinces registra el mayor rendimiento, siendo el hibrido "Dekalb 5005" el que sobresale, seguido del "Vencedor R-8330" con 7,738.0 y $6,373.7 \mathrm{~kg} \mathrm{ha}^{-1}$, respectivamente. El mayor rendimiento por hectárea en la localidad de Vinces se atribuye a la mayor longitud, número de hileras de las mazorcas y peso de semillas.

En relación al contenido de lisina de los híbridos de maíz, se determinó que con ciertos híbridos como el "Dekalb 5005" y "Vencedor R-8330" el rendimiento es inversamente proporcional a la calidad de la proteína.

Con el "INIAP H-551" se encontró un buen nivel de lisina (3.4 mg por cada $100 \mathrm{~g}$ de proteína), el cual no es alcanzado por los híbridos "Dekalb 5005", "Vencedor 8330", "Brasilia 8501" e "INIAP-552". 


\section{Literatura Citada}

Agripac (Agrícola del Pacífico, EC). s.f. Principales características agronómicas del maíz. Plegable divulgativo s.n.

Angeles, H. 1972. Obtención de variedades mejoradas de maíz de alta calidad de proteína en México. In Simposio sobre desarrollo y utilización de maíces de alto valor nutritivo. Chapingo, MX, Colegio de Posgraduados, ENA. p. $85-86$.

Bourne, J. 2007. Sueños verdes. Fabricar combustibles de productos agrícolas puede ser bueno para el planeta... tras un par de avances. Revista National Geographic en Español. Octubre de 2007. p. $22-43$

Chávez, A. 1972. El Maíz en la Nutricion de México. In Simposio sobre desarrollo y utilización de maíces de alto valor nutritivo. Chapingo, MX, Colegio de Posgraduados, ENA. p 9 - 10.

INIAP, 1990. INIAP H-551. Híbrido de maíz para la Zona Central del Litoral. Programa de maíz, EET - Pichilingue. Plegable divulgativo $\mathrm{N}^{\circ} 112$.

INIAP, 2003. INIAP H-552. Nuevo híbrido de maíz amarillo cristalino para la Zona Central del Litoral. Programa de maíz, EET - Pichilingue. Plegable divulgativo $\mathrm{N}^{\circ} 197$.

INTA (Instituto Nacional de Tecnología Agropecuaria, AR). 2006. Calidad del grano de maíz (en línea). Consultado 8 dic. 2008. Disponible en http://www. inta.gov.ar/ediciones/idia/cereales/maiz03.pdf

LiuBá, G. 2006. Evaluación agronómica de 12 híbridos de maíz (Zea mays L.) introducidos de Brasil en comparación con seis híbridos comerciales, en la zona de Quevedo durante la época lluviosa. Tesis de Ingeniero Agrónomo. Universidad Técnica Estatal de Quevedo. Los Ríos, EC. 74 p.
Martínez, A. 1996. Diseños experimentales. Métodos y elementos de teoría. Trillas. Universidad Autónoma de Chapingo. México, MX. p. $664-694$.

Poey, F. 1972. Mejoramiento genético de la calidad nutritiva del maíz. In Simposio sobre desarrollo y utilización de maíces de alto valor nutritivo. Chapingo, MX, Colegio de Posgraduados, ENA. p. $69-70$.

Poey, F. 1973. Mejoramiento genético de la calidad nutritiva del maíz. In. Simposio sobre desarrollo y utilización de maíces de alto valor nutritivo. México D.F., Colegio de Posgraduados, Chapingo, SAG. p. $69-83$.

Pradilla A, Linares F, Francis C. A. y Fajardo L. 1973. El maíz de alta lisiaba en nutrición humana. In. Simposio sobre desarrollo y utilización de maíces de alto valor nutritivo. México D.F., Colegio de Posgraduados, Chapingo, SAG. p. $41-48$.

Vasal, S.K. 1994. High quality protein corn. In A.R. Hallauer, ed. Specialty corns. Boca Raton, FL, USA, CRC Press. p. $79-121$.

Villegas, E. 1972. Maíces de alta calidad nutricional. In Simposio sobre desarrollo y utilización de maíces de alto valor nutritivo. México, Chapingo, Colegio de Posgraduados, ENA. p. 13 - 14.

Zambrano, L. 2002. Efecto de fertilización con NPK sobre el rendimiento del híbrido de maíz (Zea mays L.) Brasilia 8501 en la Zona de Balzar durante la época lluviosa del año 2002. Tesis de Ingeniero Agrónomo. Universidad Técnica Estatal de Quevedo. Los Ríos, EC. 44 p. 